\title{
Walk with a Doc - a Call to Action for Physician-Led Walking Programs
}

\author{
David Sabgir ${ }^{1,2} \cdot$ Joan Dorn ${ }^{3}$ \\ Published online: 29 May 2020 \\ (C) Springer Science+Business Media, LLC, part of Springer Nature 2020
}

\begin{abstract}
Purpose of Review An abundance of data supports the health benefits of physical activity, social connectedness, and spending time outdoors. Yet, a majority of Americans are living lives that are sedentary, lonely, and not connected with nature. We have three primary goals in writing this paper. First, we will review the well-documented health challenges arising from a sedentary, isolated lifestyle. Second, we will discuss the benefits of walking as a primary means of increasing physical activity. Finally, we will shine a light on the exponential success of Walk with a Doc, a national non-profit organization. Walk with a Doc focuses on bringing physician-led enthusiasm into our communities by organizing regular doctor-led walks in the outdoors; as well as Walk with a Future Doc, which encourages medical students to start their own Walk with a Doc programs.

Recent Findings The Physical Activity Guidelines for Americans share that physical activity is an important action that people of all ages can take to improve their health. These guidelines recommend that adults partake in at least 150 min of moderate aerobic physical activity. Currently, only $23 \%$ of Americans are achieving this amount of aerobic activity. In addition, recent data suggest that 3 in 4 people are lonely, a significant social determinant of health. Finally, over half of all Americans spend fewer than $5 \mathrm{~h}$ outside each week. Walk with a Doc and Walk with a Future Doc are having an enormous impact on combating the negative effects of these health challenges. An evaluability assessment was completed in 2018 showing Walk with a Doc attendees felt the program increased their physical activity and their social connections, with a majority of Walk with a Doc gatherings occurring in nature. Physicians and other Walk with a Doc program leaders also reported high levels of satisfaction with their participation in Walk with a Doc.

Summary As teammates in this healthcare fight, we are all painfully aware of the crisis on our hands. Of our patients, $70 \%$ are overweight or obese, nearly $80 \%$ of us are not getting enough physical activity, with all of this leading to billions of dollars in healthcare costs. Adding fuel to the fire, our doctors are burning out because of it. Today, we want to share what we have learned to be an extremely viable solution. The solution has the capacity to save 5 million lives and $\$ 68$ billion dollars per year. Additionally, it is bolstering the job satisfaction and happiness of our providers. Personally, it turned my life around in 2005, and since then, it is now greater than 560 communities around the USA (and 34 other countries). We call it, simply, Walk with a Doc.
\end{abstract}

Keywords Walking $\cdot$ Chronic disease prevention or health promotion $\cdot$ Social connectedness $\cdot$ Outdoors/nature $\cdot$ Doctor-patient relationships

This article is part of the Topical Collection on Public Health Policy

David Sabgir

david@walkwithadoc.org

Joan Dorn

JDorn@med.cuny.edu

1 Department of Cardiology, OhioHealth, Columbus, OH, USA

2 Walk with a Doc, Columbus, OH, USA

3 Department of Community Health and Social Medicine, City University of New York, New York, NY, USA

\section{Introduction}

The mental and physical health benefits of living an active lifestyle, connected with others and to nature, are well proven. Yet, many Americans struggle to meet the minimum level of recommended minutes of physical activity per week, let alone doing so in an environment that fosters human connections in our natural world.

Bringing our country together for physical activity in nature presents a whole host of challenges to the medical field. Many patients at risk for or already experiencing lifestyle- 
related chronic disease mistakenly feel that they are getting enough physical activity at work - that the weather is not conducive to them being active or that they do not have enough time for exercise. Many of these same Americans are lonely, disconnected from nature, and eager to establish social contacts and connections with the outdoors that are proven to improve the quality of their lives.

In recent years, healthcare advocates, including the 19th Surgeon General of the United States, Dr. Vivek Murthy, have challenged communities to promote walking as a way to increase physical activity. One program that has seen considerable success in meeting this challenge is Walk with a Doc, a physician-led community walking program that is free to the public and, where possible, takes place in outdoor venues such as public parks. Walk with a Future Doc, now present in 40 medical schools, was started by Walk with a Doc to encourage medical students to lead Walk with a Doc programs. Walk with a Future Doc acts as a catalyst for students to engage in community-based preventative health programs as they embark on their medical careers. Together, Walk with a Doc and Walk with a Future Doc act to reverse the negative health consequences of a sedentary lifestyle, social isolation, and disconnection from nature.

\section{The Challenge}

\section{The Statistics Behind the Epidemic}

In 2008, the Department of Health and Human Services issued its first Physical Activity Guidelines for Americans outlining the recommended amounts of physical activity required to achieve health benefits. These guidelines were updated in a second edition in 2018 after careful review of the most recent scientific literature provided convincing evidence of even more health promotion and disease prevention benefits of physical activity $[1 \bullet \bullet$. The guidelines suggest that we should move more and sit less. For substantial health benefits we should achieve:

- at least 150 to $300 \mathrm{~min}$ a week of moderate-intensity aerobic activity ( $2 \mathrm{~h}$ and $30 \mathrm{~min}$ to $5 \mathrm{~h}$ ); or

- 75 to 150 min a week of vigorous-intensity aerobic physical activity ( $1 \mathrm{~h}$ and $15 \mathrm{~min}$ to $2 \mathrm{~h}$ and $30 \mathrm{~min}$ ); or

- an equivalent combination of moderate and vigorousintensity aerobic activity.

Additional benefits can be gained by going beyond the 300 min of moderate-intensity activity noted above.

According to the revised 2018 guidelines, only $22.5 \%$ of adults $[1 \bullet \bullet$ are meeting the basic recommendations for physical activity, and less than 5\% are active for 30 mins per day [2]. The negative consequences of failing to meet these guidelines are staggering. Lack of physical activity has been proven to contribute to heart disease [3], many cancers [4], high blood pressure [5], stroke [6], type II diabetes [7], anxiety [8], depression [9], and many other illnesses. These diseases, directly impacted by sedentary lifestyles, are costing about 5 million lives/year [10] globally, almost as many as smoking (6 million). Aside from the devastation of losing 5 million people, this epidemic is costing us 67.5 billion globally. [11].

In addition to the negative impact of physical inactivity, we also know that $76 \%$ of Americans show significant signs of loneliness with $54 \%$ surveyed as moderately lonely and $22 \%$ as extremely lonely [12]. We are learning from more and more studies that we are healthier when we are together [13]. Loneliness has repeatedly been shown to act as a health risk factor. A meta-analysis in 2010 showed the influence of social relationships is comparable to other risk factors increasing mortality [14].

Finally, there has been increasing data on our lack of time outside and its negative impact on health and wellness [14]. More than half of those living in the USA spend less than $5 \mathrm{~h}$ a week in nature [15].

\section{The Benefits of Walking}

Despite the negative statistics noted above, increasing physical activity need not be difficult, particularly when focused around walking, the most popular form of physical activity. Walking requires only minimal equipment, does not require a gym membership, and is adaptable to busy lifestyles.

The health benefits of walking are abundant and cannot be overlooked. For example, walking is a proven means of reducing many of the major risk factors of heart disease, including blood sugar [16], blood pressure [17], cholesterol levels [18], and a high body mass index [19]. In addition to the cardiovascular benefits, improvements in cognitive function and memory [20], mood and stress [21], as well as longevity [22] have all been documented.

\section{Surgeon General's Call to Action on Walking}

In response to the data showing the need for increased physical activity, Dr. Vivek Murthy, the 19th Surgeon General of the United States, issued a Call to Action in 2015 [23 ••] recommending that communities could increase walking by doing the following:

- Provide safe and convenient access for all users to community locations that support walking, such as walking trails, parks, recreational facilities, and college campuses.

- Offer walking programs that address barriers, including physical limitations and safety concerns. 
- Promote the availability of safe, convenient, and welldesigned community locations and programs that promote walking.

- Offer evidence-based walking programs that are free or low cost.

- Set up walking groups, buddy systems, and other forms of social support for walking that provide multiple opportunities to walk each week.

- Encourage health care professionals to offer physical activity counseling to their patients, especially those at high risk.

\section{Facing the Challenge: Walk with a Doc and Walk with a Future Doc}

\section{Walk with a Doc}

Walk with a Doc is an innovative, preventive medicine program with the mission of inspiring communities through movement and conversation. The program is based on the four pillars of physical activity, social connectedness, education, and connecting with nature. In this way, Walk with a Doc is meeting the challenge set forth by the former surgeon general and others to provide a safe environment for communities of people to come together and walk.

Walk with a Doc was started in 2005 by Dr. David Sabgir, a cardiologist in Columbus, Ohio, as a way for Dr. Sabgir to encourage his patients to get active. He offered to meet his patients, along with anyone else from the community who wanted to participate, to take a walk in the park. The program was a success and generated interest in spreading it to other communities. Since its inception, Walk with a Doc has grown to over 540 chapters internationally. Walk with a Doc is unique in that the health care provider is physically present and active alongside the participants.

While Walk with a Doc chapters are individualized to their unique environments, they share some commonalities. Walk with a Doc gatherings are free to all participants. As regularity is critical to physical activity improving our health, all Walk with a Doc chapters are asked to meet at a minimum of once a month throughout the year (approximately $60 \%$ meet monthly, $20 \%$ weekly, and $20 \%$ bi-monthly). The physician is asked to speak for $5 \mathrm{~min}$ at the beginning of each session on any number of topics of interest to the provider or as requested by program participants. Topics may range from a current health issue in the news to ways to improve diet. Often, blood pressures are checked by healthcare personnel which, additionally, invites a healthy dialog.

At the discretion of the local Walk with a Doc chapter, fruit, water, coffee, and other healthy snacks are provided. Participants are then encouraged to walk, or, for participants in wheelchairs, to roll, at a moderate pace for the distance they are comfortable with.

In addition to the benefits to program participants, Walk with a Doc has had a positive impact on healthcare providers [24] who often report having high levels of stress and burn-out with their careers [25]. Walk with a Doc has an annual physician retention rate approximating $75 \%$, with approximately 8500 walk events in 2018 and greater than 10,000 events in 2019.

\section{Walk with a Future Doc}

In recent years, there has been interest expressed from premed and medical students in creating their own Walk with a Doc programs. In response, Walk with a Doc created Walk with a Future Doc in 2015. At Walk with a Future Doc, our future practitioners, under the direction of mentoring doctors, present discussions, check blood pressures, and walk with their local communities, in the same manner as Walk with a Doc. Walk with a Future Doc provides opportunities for students to learn firsthand about the health benefits of physical activity generally and walking in particular, while providing a powerful opportunity for medical students to engage in their communities. Walk with a Future Doc is typically implemented early in the undergraduate medical education system and is a cost- and time-effective way to weave physical activity into medical education. There are currently 40 Walk with a Future Doc programs around the world and scholarships are now in place to try and alleviate the cost burdens of implementing and maintaining these programs.

The need for programs such as Walk with a Future Doc is evident from a review of current medical school training curriculum. Despite the abundance of scientific evidence on the health benefits of physical activity, most physicians receive little to no formal training on how to talk with their patients about including adequate physical activity in their lifestyles. Unfortunately, medical schools often lack the time and resources to educate students about physical activity and other lifestyle factors that can have a major impact on health and well-being.

The need to incorporate physical activity training in medical schools and other professional health programs has been emphasized by several leaders in health care. Some notable examples include:

- The US National Physical Activity Plan, Step it Up (produced by the National Physical Activity Plan Alliance); [26]

- Step it Up! The Surgeon General's Call to Action to Promote Walking and Walkable Communities; [27]

- The American College of Sports Medicine's Exercise Is Medicine ${ }^{\mathrm{TM}}$ program; and

- The American College of Lifestyle Medicine. 
Strategies recommended in the US National Physical Activity Plan, call on institutions of higher education to nurture student interest in physical activity, provide incentives and opportunities to make it easier for students and the workforce to be more physically active, provide evidence-based resources, and include basic physical activity instruction in healthcare professional programs.

Similarly, the recent Step it Up! Surgeon General's Call to Action to Promote Walking and Walkable Communities calls upon colleges and universities to educate students and future professionals about how something as simple as walking can have important health benefits. Teaching medical students that walking is an ideal way for most Americans of all ages to meet the aerobic physical activity guidelines and encouraging those students to talk with their future patients about the health benefits of walking has the potential to help many future patients incorporate walking into a healthy lifestyle.

Organizations like the American College of Lifestyle Medicine (www.lifestylemedicine.org) and through its Exercise is Medicine program (www.exerciseismedicine.org), are working to develop and make available evidencebased curriculum to medical schools and institutions that train other health professionals. Following the lead of these organizations, Walk with a Future Doc provides a step-by-step plan for medical schools to easily incorporate a community-based program into their medical curriculum.

Walk with a Future Doc provides students with a variety of evidence-based resources on the health benefits of walking and physical activity, but there are several other important benefits. The program enables students to reap the health benefits of walking themselves by adding an opportunity to fit physical activity into the rigorous medical school curriculum. The program helps students learn to interact with members of the community and builds confidence that will serve them well in their interactions with future patients. Students also learn organizational and leadership skills by organizing walks and promoting the program on campus or in affiliated hospitals. Finally, Walk with a Future Doc helps to create a culture of health in medical schools and on campus.

In terms of the potential impact of programs such as Walk with a Future Doc, recent statistics from the Association of American Medical Colleges [28] indicate that in the USA there are 141 accredited medical schools. Together, these schools educate more than 89,000 medical students and more than 129,000 resident physicians. Given these numbers, Walk with a Future Doc has tremendous potential to enhance medical education and ultimately improve the health and well-being of current students, faculty, staff, and community partners as well as future patients and their families.

\section{Challenges and Recommendations}

Since the inception of Walk with a Doc and Walk with a Future Doc, we have learned there are some common challenges to getting the programs off the ground. One such challenge is determining a time for walks that best encourages both physician/student and community member participation. Each program will need to figure out what works best for them. One recommendation for all walks is to keep them well organized, start on time, and have the route well planned. For walks during the week, keep them to about $30 \mathrm{~min}$. For walks held on the weekend, plan for 60-90 min.

Another challenge is finding physicians or, in the case of medical schools, supervising faculty, who can commit time to the program in addition to their many other clinical and academic responsibilities. We find that identifying healthcare providers and faculty who themselves are physically active and embrace the importance of physical activity in disease prevention, management, and treatment is an effective way to keep program providers engaged and encourage long-term program success. Keeping the walks and scheduling simple and, for larger medical practices or medical schools, recruiting multiple personnel ensures coverage during the walks.

And finally, as relates specifically to Walk with a Future Doc, since medical students do not have their own practices yet, recruiting community members to walk can also be a challenge. Recommendations include publicizing the walks on schoolwide social media, creating monthly calendars so potential walkers can plan ahead, and providing t-shirts or hats to encourage attendance and raise awareness. For on campus programs that are not located in hospitals or community health centers, recruiting other university faculty, staff, students, and local neighborhood residents is essential.

\section{The Evidence Supporting Walk with a Doc and Walk with a Future Doc}

Support for the creation of Walk with a Doc and Walk with a Future Doc programs, can be gleaned from an Evaluability Assessment of Walk with a Doc programs in Ohio and Texas in 2017 [24]. The assessment was based on 244 walker surveys, 48 online physician surveys, interviews with physicians, walker focus groups, and observation of walk chapters. Respondents said they joined Walk with a Doc primarily so they could increase their physical activity, meet and spend time with other people, and listen to and learn about topics related to health. Among those surveyed, $96 \%$ of respondents strongly agreed that Walk with a Doc helped them lead a healthier lifestyle.

Aside from the statistics cited above, perhaps the most persuasive reasons to believe in the success of Walk with a Doc and Walk with a Future Doc can be drawn from quotes from program participants and leaders. The following are just a few of the many uplifting messages we have received 
regarding the impact of these programs on the lives of physicians, students, and program participants:

Walk with a Doc has been incredible for both my physical and mental health. It's an amazing de-stressor and just being outside in fresh air gives me instant relief. Walking gives me energy and it has become my meditation and daily exercise.

Myrna Villegas, Waipahu, Walk with a Doc, Oahu, Hawaii

The first Walk in Wichita Falls was exactly one month after my second back surgery. It was cloudy and freezing, but walking warmed up everyone, and the conversations and new friendships began. I am so thankful for [Walk with a Doc] in Wichita Falls.

Marcie Lowder, Walk with a Doc, Wichita Falls, TX

The question is, where do doctors learn to become doctors? Many would say that most of these lessons are learned in classrooms, labs or in hospitals with patients. I will tell you how I learned most of these skills - by walking with people in my neighborhood for thirty minutes a week.

Tracey Akanbi, Second Year Medical Student, Walk with a Future Doc, CUNY School of Medicine

[Walk with a Future Doc] has given me the opportunity to engage with the community in the most amazing way as a medical student. Every week, I get to put into practice what I am learning in the classroom to help those around me in their endeavors to improve their health. Maybe it's the walking, the talking, the people, or everything combined, but I always feel energized after a Walk with a Future Doc, like I can take on anything life throws at me that day.

Leela Rangachar, Third Year Student, Walk with a Future Doc, CUNY School of Medicine/Sophie Davis Biomedical Education Program

Walk with a Future Doc taught me the value in reaching out to the community as a health care provider. It taught me the importance of showing patients that medical professionals can be approachable and accessible outside of the health care setting. The memories and friendships I made on our weekly walks are ones I will cherish for a lifetime. Jacqueline Fleuriscar, MD, Resident, Walk with a Future Doc, University of Connecticut

I cannot tell you what today meant to me. Just to see the youth and what they are thinking about. I had a wonderful time talking to those who wanted to talk with me.
Part of the cure for the elderly is just knowing someone will listen to what they have to say.

I love being around young people that want do something that will benefit others.

I talk about them all the time, I feel like they all are my adopted children.

Neighborhood Participants, Walk with a Future Doc, Harlem, NY

\section{Conclusion}

Many of our nation's current health care challenges are triggered and exacerbated by a disturbing number of people living sedentary lifestyles, experiencing loneliness, and not spending time in nature. Walk with a Doc, an easily instituted program, is turning this around and achieving game-changing results. In sum, we encourage all individuals engaged in the healthcare industry to consider starting a Walk with a Doc program. Together, we can dramatically improve our nation's physical and mental health one step at a time.

\section{Compliance with Ethical Standards}

Conflict of Interest David Sabgir reports grants from Anthem (relationship ended in 2018) and Hass Avocado Board (2020 partnership) and grants and non-financial support from Texas Medical Association.

Joan Dorn declares no conflict of interest.

Human and Animal Rights and Informed Consent This article does not contain any studies with human or animal subjects performed by any of the authors.

\section{References}

Papers of particular interest, published recently, have been highlighted as:

- Of importance

•- Of major importance

1.• 2018 Physical Activity Guidelines Advisory Committee. 2018 physical activity guidelines advisory committee scientific report. Washington. Department of Health and Human Services, 2018. This comprehensive report provides the most current scientific evidence on the health benefits of physical activity and formed the basis for the recommendations in the physical activity

2. U.S. Department of Agriculture. Dietary guidelines for Americans. 2010.

3. Warren TY, Barry V, Hooker SP, Sui X, Church TS, Blair SN. Sedentary behaviors increase risk of cardiovascular disease mortality in men. Med Sci Sports Exerc. 2010;42(5):879-85. https://doi. org/10.1249/MSS.0b013e3181c3aa7e.

4. Patel AV, Hildebrand JS, Campbell PT, Teras LR, Craft LL, McCullough ML, et al. Leisure-Time Spent Sitting and SiteSpecific Cancer Incidence in a Large U.S. Cohort. Cancer 
Epidemiol Biomarkers Prev. 2015;24(9):1350-9. https://doi.org/ 10.1158/1055-9965.EPI-15-0237.

5. Brook RD, Appel LJ, Rubenfire M, Ogedegbe G, Bisognano JD, Elliott WJ, et al. Beyond medications and diet: alternative approaches to lowering blood pressure: a scientific statement from the American Heart Association. Hypertension. 2013;61:1360-83. https://doi.org/10.1161/HYP.0b013e318293645f.

6. Wendel-Vos GCW, Schuit AJ, Feskens EJM, Boshuizen HC, Verschuren WMM, Saris WHM, et al. Physical activity and stroke. A meta-analysis of observational data. Int J Epidemiol. 2004;33(4): 787-98. https://doi.org/10.1093/ije/dyh168.

7. Hu FB. Lipids. 2003;38:103. https://doi.org/10.1007/s11745-0031038-4.

8. Teychenne M, Costigan SA, Parker K. The association between sedentary behaviour and risk of anxiety: a systematic review. BMC Public Health. 2015;15:513. https://doi.org/10.1186/ s12889-015-1843-x.

9. Stubbs B, Vancampfort D, Firth J, Schuch FB, Hallgren M, Lee S, et al. Relationship between sedentary behavior and depression: a mediation analysis of influential factors across the lifespan among 42,469 people in low- and middle-income countries. J Affect Disord. 2018;229:231-8. https://doi.org/10.1016/j.jad.2017.12. 104.

10. Ekelund U, et al. Does physical activity attenuate, or even eliminate, the detrimental association of sitting time with mortality? A harmonised meta-analysis of data from more than 1 million men and women. Lancet. 388(10051):1302-10. https://doi.org/10.1016/ S0140-6736(16)30370-1.

11. Ingrid T. Global cost of physical inactivity is estimated at $\$ 67.5 \mathrm{bn}$ a year. BMJ. 2016;354:i4187. https://doi.org/10.1136/bmj.i4187.

12. Lee E, Depp C, Palmer B, Glorioso D, Daly R, Liu J, et al. High prevalence and adverse health effects of loneliness in communitydwelling adults across the lifespan: role of wisdom as a protective factor. Int Psychogeriatr. 2019;31(10):1447-62. https://doi.org/10. 1017/S1041610218002120.

13. House JS, Landis KR, Umberson D. Social Relationships and Health. Science. 1988;241(4865):540-5. https://doi.org/10.1126/ science.3399889.

14. Holt-Lunstad J, Smith TB, Layton JB. Social relationships and mortality risk: a meta-analytic review. PLoS Med. 2010;7(7): e1000316. https://doi.org/10.1371/journal.pmed.1000316.

15. Kellert, SR, Case DJ. A national initiative to understand and connect Americans and nature. The Nature of Americans National Report. 2017.

16. Williams PT, Thompson PD. Walking versus running for hypertension, cholesterol, and diabetes mellitus risk reduction. Arterioscler Thromb Vasc Biol. 2013;33(5):1085-91. https://doi.org/10.1161/ ATVBAHA.112.300878.
17. Wheeler MJ, Dunstan DW, Ellis KA, et al. Effect of morning exercise with or without breaks in prolonged sitting on blood pressure in older overweight/obese adults. Hypertension. 2019;73:859-67. https://doi.org/10.1161/HYPERTENSIONAHA.118.12373.

18. Ready AE, Drinkwater DT, Ducas J, Fitzpatrick DW, Brereton DG, Oades SC. Walking program reduces elevated cholesterol in women postmenopause. Can J Cardiol. 1995;11(10):905-12.

19. Tigbe WW, Granat MH, Sattar N, Lean MEJ. Time spent in sedentary posture is associated with waist circumference and cardiovascular risk. Int J Obes. 2017;41(5):689-96. https://doi.org/10.1038/ ijo.2017.30.

20. Shu Nishiguchi PT, Minoru Yamada PT, Takanori Tanigawa OT. MScA 12-week physical and cognitive exercise program can improve cognitive function and neural efficiency in communitydwelling older adults: A randomized controlled trial. J Am Geriatr Soc. 2015. https://doi.org/10.1111/jgs. 13481.

21. Aspinall P, Mavros P, Coyne R, et al. The urban brain: analysing outdoor physical activity with mobile EEG. Br J Sports Med. 2015;49:272-6.

22. Kelly P, Kahlmeier S, Götschi T. Systematic review and metaanalysis of reduction in all-cause mortality from walking and cycling and shape of dose response relationship. Int J Behav Nutr Phys Act. 2014;11(1):1. https://doi.org/10.1186/s12966-014-0132$\mathrm{x}$.

23.• U.S. Department of Health and Human Services. Step It Up! The surgeon general's call to action to promote walking and walkable communities. Washington. Dept of Health and Human Services, Office of the Surgeon General. 2015. This document provides scientific evidence for the health benefits of walking and recommends evidence-based programs and policies that have been shown to increase walking.

24. Karissa Horton, Ph.D., Jennifer Loyo, Ph.D., R.D.N. Walk with a Doc Evaluability Assessment. 2017.

25. Shanafelt TD, et al. Changes in burnout and satisfaction with worklife integration in physicians and the general US working population between 2011 and 2017. Mayo Clinic Proc. 94(9):1681-94.

26. National Physical Activity Plan Alliance. The 2018 United States report card on physical activity for children and youth. Washington: National Physical Activity Plan Alliance, 2018.

27. The surgeon general's call to action to promote walking and walkable communities. Washington. Dept of Health and Human Services, Office of the Surgeon General; 2015.

28. Results of the 2018 medical school enrollment survey. Association of American Medical Colleges.

Publisher's Note Springer Nature remains neutral with regard to jurisdictional claims in published maps and institutional affiliations. 